\title{
Isolation, identification and antimicrobial suscep- tibility profiles of Salmonella isolates from dairy farms in and around Modjo town, Ethiopia
}

\author{
Fufa Abunna*, Debebe Ashenafi, Takele Beyene, Dinka Ayana, Bedaso Mamo and Reta \\ Duguma \\ Addis Ababa University, College of Veterinary Medicine and Agriculture, P.O. Box 34, Bishoftu, \\ Oromia, Ethiopia \\ *corresponding author: e-mail fufa.abunna@aau.edu.et, mobile: +251-911899435 \\ https: / /dx.doi.org/10.4314/evj.v21i2.7
}

\begin{abstract}
Foodborne bacterial diseases are a serious challenge to human and animal health. Salmonella is a zoonotic foodborne pathogen and the etiologic agent of salmonellosis. A cross-sectional study was conducted from January 2016 to April 2016 on small scale and large scale dairy farms in and around Modjo town, Ethiopia. The main objectives of the study were to isolate and identify Salmonella from lactating cows, personnel's' and equipment at farms and to determine the in vitro antimicrobial resistance profiles of the isolates. A total of 266 samples consisting of fresh cow milk, fecal sample, pooled milkers' hand swab, pooled bucket swab, tank swab, and tank milk were collected from 21 dairy farms ( $\mathrm{n}=20$ smallholders, $\mathrm{n}=1$ large scale farm). The samples were examined for the presence of Salmonella following standard techniques and procedures outlined by the International Organization for Standardization. Kibry-Bauer disk diffusion test was used for the antimicrobial susceptibility testing. Salmonella was isolated from 28/266 (10.5\%) of the total samples. Out of the 28 Salmonella isolates, 18 (64.3\%), $3(10.7 \%)$ and 7(25\%) were from lactating cows, personnel's', and equipment, respectively. Out of the 28 isolates subjected to antimicrobial susceptibility testing, all isolates were resistant to at least one or more antimicrobials tested. Accordingly, 96.4\% (27/28), 82.1\% (23/28) and $75.0 \%(21 / 28)$ isolates were resistant to tetracycline, kanamycin and nalidixic acid, respectively. Multiple drug resistance (resistance to two or more antimicrobials) was detected in $27(96.4 \%)$ of the isolates. Multiple antimicrobial resistance was observed in 100\% (18/18), 7.4\% (2/23) and 100\% (7/7) of isolates obtained from lactating cows, personnels', and equipment, respectively. High proportion of multiple antimicrobial resistant isolates (96.4\%) in
\end{abstract}


the dairy farms alerts concern for animal and public health as these drugs is used widely for treatment and prophylaxis in animals and humans.

Keywords: Antimicrobials; Dairy farms; Isolation; Modjo; Multidrug resistance; Salmonella

\section{Introduction}

Foodborne diseases are a public health problem in developed and developing countries. More than 250 different foodborne diseases have been described. Most of these diseases are infections caused by a variety of bacteria, viruses and parasites. Other diseases are poisonings, caused by harmful toxins or chemicals like poisonous mushrooms (CDC, 2005). Bacteria that cause foodborne diseases include Salmonella, Campylobacter, Listeria, pathogenic Escherichia coli, Yersinia, Shigella and Enterobacter. Foodborne bacterial diseases are a serious challenge to human and animal health. Salmonella is a zoonotic foodborne pathogen. Salmonellosis is a major bacterial enteric illness in both humans and animals and it is the most common foodborne bacterial disease worldwide (Forshell and Wierup, 2006).

Salmonella species belong to Gram negative, rod shaped, facultative intracellular bacteria that successfully infects a wide variety of hosts. Salmonella is comprised of two species, Salmonella bongori and Salmonella enterica (Guibourdenche et al., 2010). Based on the bacterial outer membrane surface 'O' antigen, and flagellar ' $\mathrm{H}$ ' antigen more than 2,700 different serovars of Salmonella has been characterized (Collazo and Galan 1997). Out of these 2,700 serovars, nearly 1500 belong to the Salmonella enterica subsp. enterica. Serovars of the enterica sub species can be divided into three groups depending upon their ability to infect a wide variety of hosts: Serovars which have a broad host range also called as unrestricted serovars as these infect nearly all animals and pose a greater zoonotic potential than their other counterparts (Salmonella Typhimurium and Salmonella Enteritidis) (Bäumler et al., 1998), Serovars which accidentally infect hosts other than their most adapted or preferred (Salmonella Dublin and Salmonella Choleraesuis) (McCuddin et al., 2006), and serovars which are restricted to one specific host only (Salmonella Typhi and Salmonella Gallinarum) (Uzzau et al., 2001). 
Salmonella is transmitted to animals and humans through the fecal-oral route. Animals can become infected after ingestion of feed and water contaminated with Salmonella. Similarly, humans can become infected by foodborne transmission or after direct or indirect contact with infected animals (Hoelzer et al., 2011), consumption of contaminated food products (milk, eggs, and meats), cross contamination through direct contact of foods to contaminated surfaces such as stainless steel, hanging material, knife, bucket where milk are collected are a key mechanism for pathogens to contaminate food products (Kusumaningrum et al., 2003; Plym and Wierup, 2006). In livestock, clinical signs, typically appear 6-24 h after exposure and include profuse diarrhea, fever, dehydration, in appetence, foul-smelling feces, and mucus or blood in feces (Cummings et al., 2010). Disease manifestations in people include diarrhea, fever, abdominal cramps and septicemia in severe cases, appearing $12-72 \mathrm{~h}$ after ingestion. Salmonella can also be subclinical in both humans and animals (Murase et al., 2000).

Despite the controls that have already been put into place, Salmonella infection arising from contaminated food continues to be an immense problem with millions of cases occurring annually throughout the world. In addition to the misery caused, financial loss is enormous (Hendriksen, 2003). Salmonellosis is a costly disease to dairy producers on account of mortality, treatment expenses, reduced milk yield, and weight loss within the herd. Infected cattle can be either clinical or subclinical, shedding Salmonella in their faeces. Thus dairy producers need to be aware that Salmonella can be found on their farms within apparently healthy cows, which is important in terms of food safety risks (Callaway et al., 2005). Using antimicrobial agents for cattle have been implicated as a source of human infection with antimicrobial resistant (AMR) Salmonella through direct contact with livestock and consumption of raw milk, meat and contaminated materials (Alexander et al., 2009). Antimicrobial resistant Salmonella are increasing due to the use of antimicrobial agents in food animals at subtherapeutic level or prophylactic doses for growth promotion and markedly increase the human health risks associated with consumption of contaminated milk and meat products (Endrias Zewdu and Cornelius 2009), through mutation, acquisition of resistance encoding genes (Fluit, 2005) and irrational use of antimicrobials in food animals (Fluit, 2005; Takele Beyene and Berihun Tesega, 2014). 
Different studies conducted in Ethiopia revealed fragmented substantial prevalence as well as antimicrobial susceptibility of Salmonella in veterinary and public health setups (Daniel Alemayehu et al., 2003; Bayleyegn Molla et al., 2003; Getahun Ejeta et al., 2004; Wassie Molla et al., 2006; Endrias Zewdu and Cornelius, (2009); Zelalem Addis et al., 2011; Deresse Hailu et al., 2015; Takele Beyene et al., 2016). However, reports from coinciding study on apparently healthy animals at farm level, personnel and equipment used in the farms is limited especially in the current study area. The screening of milk and other dairy products for pathogenic organisms will play a vital role in curtailing human infection. Investigation of the prevalence and antimicrobial resistance of Salmonella from cattle and in contact human in dairy farms is of paramount importance to design methods to minimize the possible transmission of Salmonella between humans and cattle. Moreover, it is also important in combating the emergence of antibiotic resistant strains of Salmonella (Zelalem Addis et al., 2011). Therefore, the aims of the current study were to isolate Salmonella from dairy cows, personnel hand and equipment and evaluate the antibiogram pattern of the isolates in selected dairy farms in and around Modjo town.

\section{Materials and Methods}

\section{Study area}

The study was conducted in and around Modjo town from January 2016 to April 2016. Modjo is the administrative center of Lome district, located in the East Shewa Zone of the Oromia Region, Ethiopia. It is located at $66 \mathrm{Km}$ Southeast of Addis Ababa and lies at latitude $8^{\circ} 35^{\prime} \mathrm{N}$ and longitude $39^{\circ} 7^{\prime} \mathrm{E}$ at an altitude of 1790 meters above sea level. The area gain rainfall twice a year those known as long and short rainy season. The main rainy season extends from June to September. The average annual rainfall, temperature, and mean relative humidity are: $776 \mathrm{~mm}, 19.4{ }^{\circ} \mathrm{C}$ and $59.9 \%$ respectively (CSA, 2005).

\section{Study population}

The study population is lactating dairy cows in Modjo town and the study animals were apparently healthy dairy cows in small and large scale dairy farms located in and around Modjo town. The farms were selected by using simple random sampling strategies based on data obtained from the Lome district livestock and fishery resource development. The study populations were divided according to their location as urban (Modjo town) and peri-urban (the sur- 
rounding area within Lome district). In this study, the majority of farms found in the study area were small scale having herd sizes not more than six cows. All of the available lactating cows present in each farm were sampled except the one large scale dairy farm in which cows were sampled by simple random sampling. According to personal observation, the hygienic status of the cows and their environment was more or less good even though some animals were reared under poor hygienic condition plus in a manner mixed with other activities of the households. Farm equipment used in the milking and storage of milk and personnel's (milkers) were also part of the study.

\section{Study design}

A cross-sectional study was carried out to isolate, identify and detect antimicrobial susceptibility profile of the Salmonella from dairy farms. Sampling days were randomly assigned and each farm was visited only once during the study period. Types of sample collected include udder milk, tank milk, pooled milkers' hand swab, pooled buckets swab and tank swab. Prior to sample collection, cooperation letter was sent to Lome district livestock and fishery resource development bureau and animal health technician was assigned and sampling in each dairy farm was undertaken in collaboration with them.

\section{Sampling and sample size determination}

The farms were randomly selected for this study based on the availability and accessibility of study animals. All animals fulfilling the inclusion criteria (apparently health animals) were considered. The minimum sample size was calculated by using the formula given by Thrusfield (2007): $n=Z^{2} p(1-p) / d 2$ where $\mathrm{n}=$ sample size, $\mathrm{p}$ (expected prevalence) $=28.6 \%$ (Zelalem Addis et al., 2011), d (absolute precision) $=0.05$ at $95 \%$ confidence interval. Accordingly, the sample size was calculated to be 314 . However, in this study, a total of 266 samples were collected (because of unwillingness of the owners, inaccessibility of farms and limited resources) from twenty small scales (less than 20 dairy cows) and one large scale (more than 20 dairy cows) selected dairy farms for all sample types.

\section{Sample collection and transportation}

Samples from dairy cows (milk and faeces), hands of personnel working in the farms (milkers) and from equipment were aseptically collected from the se- 
lected dairy farms. Samples from dairy cows were collected from apparently health lactating cows. Fresh faecal samples were collected directly from the rectum of healthy lactating dairy cows using disposable gloves in to sterile plastic bags. Milk samples were collected after the teats were scrubbed vigorously with a pledge of cotton moistened with $70 \%$ ethyl alcohol and the first 3-4 streams of milk were discarded. The nearest teats were sampled first, then toward far ones. The collecting vial was held as near horizontal as possible and by turning the teat to a near horizontal position. Approximately $10 \mathrm{ml}$ of milk was collected aseptically from all teats in a sterile test tube. Pooled milkers' hand swab, tank swab, and pooled buckets swab were collected before the beginning of milking process by using a sterile cotton swab.

Samples were properly coded based on collection date, sample source and sample type. Source of sample was classified as animal, personnel and equipment. Types of samples collected in quantity were udder milk (91), faeces (91), pooled milkers' hand swab (21), pooled buckets swab (21), tank swab (21) and tank milk (21). A total of 266 samples were collected from animals ( $\mathrm{n}=182)$, personnel $(n=21)$, and equipment $(n=63)$. Samples were collected early in the morning around 6:00 to 7:00 AM and in the afternoon around 4:00 to 6:00 PM by arranging time in communication with the milkers' and owners of the farms. Then samples were immediately transported under cold condition (ice box) to the Microbiology Laboratory of College of Veterinary Medicine and Agriculture, Addis Ababa University, Bishoftu, which is about $20 \mathrm{~km}$ from sampling area for culturing. Upon arrival, samples were processed separately by preenriching in pre-enrichment media or were stored overnight in a refrigerator at $+4^{\circ} \mathrm{C}$ until examined the next day. Then further processes were followed after samples were incubated for $24 \mathrm{hrs}$.

\section{Isolation and identification of Salmonella}

The isolation and identification of Salmonella was performed at the Microbiology laboratory of College of Veterinary Medicine and Agriculture, Addis Ababa University by using techniques recommended by International Organizations for Standardization (ISO-6579, 2002), and those recommended by the World Health organization (WHO) Global foodborne infections network (formerly WHO global Salmonella Surveillance) (WHO, 2010; Hendriksen, 2003). The detection of Salmonella necessitates four successive stages: Upon arrival or thawed refrigerated samples were processed separately and the appropriate size of processed samples (25g) are incubated within $225 \mathrm{ml}$ of Buffered pep- 
tone water for pre-enrichment purposes (1:9)(CONDA Cat,1402.00, England) at $37 \pm 1^{\circ} \mathrm{C}$ for $18 \pm 2 \mathrm{hrs}$. Tetrathionate Broth (TM MEDIA, India) and Rappaport Vassiliadis Salmonella Enrichment Broth (HIMEDIA, India) were used for selective enrichment of all samples whereas Xylose lysine Desoxycholate agar (OXOID CM0469, England) and Salmonella-Shigella (SS) agar (OXOID CM0099, England) plates were used for plating out and identification purpose. For confirmation, five presumptive Salmonella colonies (or less depending on availability) were selected from every selective plating media. The selected colonies were streaked onto the surface of pre-dried Nutrient agar (OXOID CM0003, England) plates in a manner that allow isolated colonies to develop and incubated at $37 \pm 1^{\circ} \mathrm{C}$ for $24 \pm 3 \mathrm{hrs}$ for further confirmation with biochemical tests. All suspected Salmonella colonies were picked from the nutrient agar and inoculated into the following biochemical tubes for identification: tryptone soya broth (OXOID CM0129, England), triple sugar iron (OXOID CM0277, England) agar, Simmon's citrate agar (HIMEDIA M099, India), urea broth (HIMEDIA M111A, India), Methyl red-Voges-Proskauer (HIMEDIA M070, India) broth and then incubated for 24 to $48 \mathrm{hrs}$ at $37^{\circ} \mathrm{C}$.

\section{Antimicrobial susceptibility test}

The antibiotic susceptibility tests of the Salmonella isolates were performed according to the Clinical and Laboratory Standards Institute guidelines (CLSI, 2006) by using Kibry-Bauer disk diffusion test on Muller-Hinton agar (OXOID CM0337, England). Pure colonies on nutrient agar were taken with a wire loop and transferred to a tube containing $5 \mathrm{ml}$ of saline water and emulsified. The broth culture was incubated at $37^{\circ} \mathrm{C}$ for $4 \mathrm{hrs}$ until it achieved the $0.5 \mathrm{McFar}$ land turbidity standards. Sterile cotton swab was dipped into the suspension and the bacteria were swabbed uniformly over the surface of Muller- Hinton agar plate within a sterile safety cabinet. The plates were held at room temperature for 15 minutes to allow drying. Antibiotic discs with known concentration of antimicrobials were placed and the plates were incubated for $24 \mathrm{hrs}$ at $37^{\circ} \mathrm{C}$.

Each isolate was tested for a series of eleven antimicrobials. amoxicillin (AML) $(25 \mu \mathrm{g})$, ampicillin (AMP) $(10 \mu \mathrm{g})$, cefoxitin (FOX) (30 $\mu \mathrm{g})$, chloramphenicol (C) $(30 \mu \mathrm{g})$, gentamycin $(\mathrm{CN})(10 \mu \mathrm{g})$, streptomycin $(\mathrm{S})(10 \mu \mathrm{g})$, kanamycin $(\mathrm{K})(30$ $\mu g)$, nalidixic acid (NA) $(30 \mu g)$, ciprofloxacin (CIP) (5 $\mu \mathrm{g})$, tetracycline (TE) (30 $\mu \mathrm{g})$ and trimethoprim-sulphamethaxazole (SXT) $(25 \mu \mathrm{g})$, all from Oxoid com- 
pany, England. Following incubation, the diameters of clear zones produced by antimicrobial inhibition of bacterial growth were measured to the nearest $\mathrm{mm}$ for each disc using transparent straight line ruler and then classified as resistant, intermediate, or susceptible according to published interpretive chart of CLSI.

\section{Data management and analysis}

Data was analyzed by using Stata version 12 (2011, College Station, TX: StataCorp LP, USA). Descriptive analysis was used to describe the result of proportion analysis. Proportion was estimated as the number of samples detected positive to Salmonella isolation from the total sample analyzed. Chi-square test was done to study association between Salmonella isolates and variables considered (sampling area, sample source, sample type and herd size). The significance level was set at 0.05 .

\section{Results}

Salmonella was isolated from 28/266 (10.5\%) of the total samples. Out of the 28 Salmonella isolates, 18 (64.3\%), 3 (10.7\%), (and 7(25\%) were from lactating cows, personnel's', and equipment, respectively.

From a total of 21 dairy farms included in the current study, Salmonella was isolated from 17 (80.95\%) farms. From a total of 91 lactating cows examined, $17.6 \%$ (16/91) were positive for Salmonella either from milk or faecal samples or both. From the cows confirmed Salmonella positive, $68.75 \%$ (11/16) were positive from milk sample and $43.75 \%$ (7/16) were positive from faecal sample. Two cows were positive both from the faeces and milk sample. There is no statistically significant difference between isolates derived from milk and faecal samples of studied dairy cows $(x 2=3.709, \mathrm{p}=0.592)$ (Table 1$)$.

Table 1. Distribution of Salmonella isolates in dairy farms

\begin{tabular}{lcc}
\hline Sample types & Number of samples & \\
\hline & Examined & Positive (\%) \\
\cline { 2 - 3 } Udder milk & 91 & $11(12.1)$ \\
Fecal sample & 91 & $7(7.7)$ \\
Hand swab & 21 & $3(14.3)$ \\
Bucket swab & 21 & $2(9.5)$ \\
Tank swab & 21 & $1(4.8)$ \\
Tank milk & 21 & $4(19.0)$ \\
Total & 266 & $28(10.5)$ \\
\hline
\end{tabular}


All the 28 isolates were tested against eleven commonly used antimicrobials. All isolates were resistant at least to one or more antimicrobials. Twenty seven of the 28 isolates were resistant to two or more antimicrobials. The antibiotic susceptibility profiles of the isolates showed that the isolates were $96.4 \%$, $82.1 \%$ and $75.0 \%$ resistant to tetracycline, kanamycin and nalidixic acid, respectively. On the other hand, all isolates were $100 \%$ sensitive to gentamicin and ciprofloxacin (Table 2).

Table 2. Antibiotic Susceptibility Profiles of Salmonella isolates in dairy farms

\begin{tabular}{lccc}
\hline Antimicrobials & \multicolumn{3}{c}{ Antibiotic Susceptibility profile } \\
\cline { 2 - 4 } & No.sensitive (\%) & $\begin{array}{c}\text { No. intermediate } \\
\text { (\%) }\end{array}$ & No. resistant (\%) \\
\cline { 2 - 4 } Kanamycin & $2(7.1)$ & $3(10.7)$ & $23(82.1)$ \\
Nalidixic acid & $0(0.00)$ & $7(25.0)$ & $21(75.0)$ \\
Gentamicin & $28(100.0)$ & $0(0.00)$ & $0(0.00)$ \\
Cefoxitin & $25(89.3)$ & $0(0.00)$ & $3(10.7)$ \\
Streptomycin & $16(57.1)$ & $9(32.1)$ & $3(10.7)$ \\
Chloramphenicol & $14(50.0)$ & $9(32.1)$ & $5(17.9)$ \\
Tetracycline & $0(0.00)$ & $1(3.6)$ & $27(96.4)$ \\
Amoxicillin & $10(35.7)$ & $11(39.3)$ & $7(25.0)$ \\
Ampicillin & $17(60.7)$ & $0(0.00)$ & $11(39.3)$ \\
Ciprofloxacin & $28(100)$ & $0(0.00)$ & $0(0)$ \\
Trimethoprim- & $22(78.6)$ & $3(10.7)$ & $3(10.7)$ \\
Sulfamethoxazole & & & \\
\hline
\end{tabular}

Multiple antimicrobial resistances(resistance to two or more antimicrobials) was detected in $96.4 \%$ (27/28) of the isolates. A total of seven different antimicrobial resistance patterns were observed (Table 3). 
Table 3. Antimicrobial resistance patterns of Salmonella isolates

\begin{tabular}{lll}
\hline Number of antimicrobial resistance & $\begin{array}{l}\text { Antimicrobial resistance } \\
\text { patterns (number of } \\
\text { isolates) }\end{array}$ & $\begin{array}{l}\text { Number of } \\
\text { isolates (\%) }\end{array}$ \\
\hline Two & NA, TE (3) & $5(18.5)$ \\
K, TE (2) & K, NA, TE (7) \\
Khree & K, TE, AMP (1) & $8(29.6)$ \\
Four & K, NA, TE, AMP (2) & $7(25.9)$ \\
& C, TE, AMP, (1) & \\
& NA, TE, AML,AMP (1) & \\
& K, NA, TE, SXT (1) \\
& K, TE, AML, SXT (1) & \\
Kive & K, NA, S, TE (1) & \\
& K,NA, C, TE, AMP (1) & $4(14.8)$ \\
K, NA, TE, AML, AMP (2) & \\
Kix & K, NA, FOX, C, TE (1) & \\
Seven & K, NA,C,TE,AML,AMP,SXT & $1(3.7)$ \\
& $(1)$ & \\
Eight & K, NA, FOX, S, C, TE, AML, & $1(3.7)$ \\
& AMP (1) &
\end{tabular}

Key: K (Kanamycin), NA (Nalidixic acid), CN (Gentamicin), FOX (Cefoxitin), S (Streptomycin), C (Chloramphenicol), TE (Tetracycline), AML (Amoxicillin), AMP (ampicillin), CIP (Ciprofloxacin), SXT (Trimethoprim-sulfamethoxazole).

From total isolates derived from all three sources, $96.4 \%$ of the isolates were resistant to two or more of the antimicrobials tested. The isolates from milk samples were $100 \%$ resistant to tetracycline and $81.8 \%$ resistant to nalidixic acid and kanamycin. On the other hand, all isolates from feces were $100 \%$ resistant to tetracycline and $85.7 \%$ of the isolates were resistant to kanamycin and nalidixic acid.

\section{Discussion}

Salmonella infection in dairy cattle persists to be a major problem worldwide. Considerable economic losses were manifested through mortality and poor growth of infected animals as well as the risk of transmission to humans either through food chain or direct animal contact. Hence, detection of animals contacting humans and equipment are essential to control Salmonella on-farm and its spread to the public (Plym and Wierup, 2006; Rotimi et al., 2008). The 
proportion of Salmonella isolated in this study (10.5\%) is lower than 20\% in raw milk from Kersa district; Ethiopia (Teshome Tadesse and Anbessa Dabassa, 2012). This difference may be attributed to the difference in the source of sample. But, it is consistent with $10.76 \%$ in lactating cows and in contact humans in dairy farms of Addis Ababa (Zelalem Addis et al., 2011).

In this study the prevalence of Salmonella in apparently healthy lactating dairy cows (milk and faecal samples) (17.6\%) is higher than a similar report in Gondar town (12.5\%) (Deresse Hailu et al., 2015). Hence lactating cows could be potential sources of Salmonella infection for individuals working in dairy farms and for the community at large. Fecal prevalence of Salmonella among lactating dairy cattle in the current study was $7.7 \%$ (7/91) which is interestingly similar with the fecal Salmonella isolation rate of $7.7 \%$ in lactating cows and in contact humans in dairy farms of Addis Ababa (Zelalem Addis et al., 2011) and $7.3 \%$ in dairy cows in USA (Blau et al., 2005). However, it is lower than the fecal Salmonella isolation rate of 9.7\% in United States (Callaway et al., 2005). This study also disagrees with a report of $1.56 \%$ prevalence in Egypt on fecal shedding of Salmonella among dairy cattle (Mohamed et al., 2011). The current study also revealed $14.3 \%$ of Salmonella isolates from pooled milkers' hand swab which is lower than that reported by Takele Beyene et al. 2016 (28.6\%) from Asella Municipal abattoir but higher than the work of Akafete Teklu and Haileleul Negussie (2011) 8.9\% in slaughtered small ruminants and environment in Modjo export abattoir.

The difference in amount and relative occurrence of Salmonella isolate between the present and previous studies at different areas of the Ethiopia could be attributed to difference in risk factors that contribute to the occurrence of Salmonella. These are host related risk factors that include age, breed, the physiological state of the animals, feeding strategies, vaccination status (Liza, 2003). Environment related risk factors such as hygienic and management practice, stocking density, type and amounts of feed, accessible water supplies, usage of contaminated utensils, housing type, ventilation, movement of animals, calving environment, and production facilities in different areas also play role for Salmonella occurrence (Karin et al., 2011).

Antimicrobial use in animal production systems has long been suspected to be a cause of the emergence and dissemination of antimicrobial resistant Salmonella. Improper use of antimicrobials in both human and veterinary medicine 
has contributed to development and dissemination of antimicrobial resistant pathogens (Zelalem Addis et al., 2011; Tajbakhsh et al., 2012). In this study, resistance to two or more of antimicrobials (96.4\%) was observed. This is higher than studies conducted in Ethiopia (Zelalem Addis et al., 2011; Endrias Zewdu and Cornelius, 2009; Abebe Mekuria et al., 2014; Teshome Tadesse and Anbessa Dabassa, 2012; Anbessa Dabassa and Ketema Bacha, 2012; Fadlalla et al (2012) from Sudan, Stevens et al.(2006) from Senegal, and Lagos, Nigeria (Stella et al., 2009). This difference may be due to the increasing rate of inappropriate utilization of antimicrobials in the dairy farms which favors selection pressure that increased the advantage of maintaining strains of bacteria carrying resistance genes (McGeer et al., 1998; Mathew et al., 2006). A study in Alexandria Egypt (Mohamed et al., 2011) reported that $85.7 \%$ of Salmonella species isolated from dairy cattle were sensitive to ampicillin and tetracycline. This result strongly disagrees with the current study in which $96.4 \%$ and $39 \%$ of the isolates were resistant to tetracycline and ampicillin, respectively. Resistance rates to ampicillin and tetracycline is very high when compared to results documented in America (Blau et al., 2005) reported as $4.4 \%$ and $12.2 \%$ resistance levels, respectively.

This finding is in line with a report in Sudan (Fadlalla et al., 2012) in which Salmonella isolates from human and cattle were $100 \%$ susceptible to ciprofloxacin. The high sensitivity rate observed among Salmonella isolates in the current study to gentamicin and ciprofloxacin (100\%) which is higher than $73.3 \%$ and $83.3 \%$ reported by Zelalem Addis et al. 2011 and $75 \%$ and $95 \%$ reported by Teshome Tadesse and Anbessa Dabassa, 2012; for both antimicrobial agents, respectively might be due to difference in sample size, presence of different strain of the bacteria, difference in frequency and dosage of drugs used.

A single isolate from fecal sample was MDR to 8 antimicrobials namely kanamycin, nalidixic acid, cefoxitin, streptomycin, chloramphenicol, tetracycline, ampicillin, and amoxicillin followed by an isolate from udder milk resistant to seven antimicrobials: kanamycin, nalidixic acid, chloramphenicol, tetracycline, ampicillin, amoxicillin, and trimethoprim-sulphamethaxazole. The possible reason for high rate of AMR level of Salmonella might be due to the increasing rate of irrational use of antimicrobials in the dairy farms, frequent usage both in livestock and public health, use of counterfeit drugs in animal husbandry (Guthrie, 1992), self-medication due to easy access to antimicrobials without prescription in public health sector and administration of subtherapeutic dose 
of antimicrobials to livestock for prophylactic or nutritional purpose in food animals (Acha and Szyfers, 2001; Tadesse Birhanu et al., 2014).

Antimicrobial-resistant Salmonella in raw milk may be able to colonize the gut if consumed by humans, thus making infections difficult to treat. Evidence (Mahami et al., 2011; Akoachere et al., 2009) indicates that the global rise of antimicrobial resistance is mainly due to indiscriminate use of drug for treatment of both human and animal diseases.

\section{Conclusion}

The isolation of $10.5 \%$ Salmonella at dairy farms level showed that dairy cattle and their environment are important sources of milk contamination. Detection of high proportion of multiple antimicrobial resistant isolates (96.4\%) in the dairy farms alerts concern for animal and public health as these drugs are used widely for treatment and prophylaxis of various bacterial infections in animals and humans.

\section{Acknowledgments}

The authors are grateful to Addis Ababa University for the provision of financial assistance and necessary facilities to conduct the research work. Authors are also thankful to dairy farm owners for their willingness during sample collection.

\section{References}

Abebe, M., Tafese, B. and Adane, H., 2014. Antimicrobial resistance of Salmonella Serovars isolated from food of bovine origin in selected Woredas of Tigray, Ethiopia. J. World Med. Sci., 11, 342-347.

Acha, P. and Szyfers, B., 2001. Zoonoses and Communicable Diseases Common to Man and Animals. Bacteriosis and Mycosis, Washington DC, Pan American Health Organization.

Addis, Z., Kebede, N., Worku, Z., Gezahegn, H., Yirsaw, A., 2011. Prevalence and an-timicrobial resistance of Salmonella isolated from lactating cows and in contact humans in dairy farms of Addis Ababa: a cross sectional study. BMC Infect. Dis., 11, 222. 
Akoachere, T., Tanih, F., Ndip, M. and Ndip, N., 2009. Phenotypic Characterization of Salmonella Typhimurium Isolates from Food-animals and Abattoir Drains in Buea, Cameroon. J. Health Popul. Nutr., 27, 1-7.

Alemayehu, D., Molla, B. and Muckle, A., 2003. Prevalence and antimicrobial resistance pattern of Salmonella isolates from apparently healthy slaughtered cattle in Ethiopia. Trop. Anim. Hlth. Prod, 35, 309-319.

Alexander, K., Warnick, L. and Wiedmannm, M., 2009._Antimicrobial resistant Salmonella in dairy cattle in the United States. Vet. Res. Commun., 33, 191-209.

Bäumler, A., Tsolis, R., Ficht, T. and Adams, L., 1998. Evolution of host adaptation in Salmonella enterica. Infect. Immun., 66, 4579-4587

Beyene, T and Tesega, B., 2014. Rational veterinary drug use: Its significance in public health. J. Vet. Med. Hlth., 6, 302-308.

Beyene, T., Yibeltie, H., Chebo, B., Abunna, F., Beyi, A., Mammo, B.,Ayana, D. and Duguma, R., 2016. Identification and antimicrobial susceptibility profile of Salmonella isolated from selected dairy farms, abattoir and humans at Asella town, Ethiopia. J. Vet. Sci. Techno., 7, 320.

Birhanu, T., Abda, S. and Gebrezgabiher, G., 2014._Prevalence of Salmonella on Sheep carcasses slaughtered at Adama municipal abattoir, South Eastern Ethiopia. J. Sci. Technol. Arts Res., 3,107-111.

Blau, D., McCluskey, B., Ladely, S., Dargatz, D., Fedorka-Cray, P., Ferris, K. and Headrick, M., 2005. Salmonella in Dairy Operations in the United States: Prevalence and antimicrobial drug susceptibility. J. Food. Prot. 68, 696-702.

Callaway, T., Keen, J., Edrington, T., Baumgard, L., Spicer, L., Fonda, E., Griswold, K., Overton, T., Vanamburgh, M., Anderson, R., Genovese, K., Poole, T., Harvey, R. and Nisbet, D., 2005. Fecal prevalence and diversity of Salmonella species in lactating dairy cattle in four states. J. Dairy Sci., 88, 3603-3608.

Center for Disease Control (CDC) 2005. Food borne illness, January 10: 1-13.

Central Statistical Agency (CSA), 2005. Agricultural Sample Survey 2004/05. Central Statistical Authority No.2. Report on Livestock and livestock characteristics. Statistical Bulletin, Addis Ababa, Ethiopia, Pp. 331.

Clinical and Laboratory Standards Institute (CLSI), 2006. Performance Standards for Antimicrobial Susceptibility Testing; Sixteenth Informational Supplement. 940 West Valley Road, Suite 1400, Wayne, Pennsylvania 19087-1898 USA.

Collazo, C. and Galan, J., 1997. The invasion-associated type-III protein secretion system in Salmonella-a review. Gene, 192,51-59. 
Cummings, K., Warnick, L., Elton, M., Grohn, Y., McDonough, P. and Siler, J., 2010. The effect of clinical outbreaks of Salmonellosis on the prevalence of fecal Salmonella shedding among dairy cattle in New York. Foodborne Pathog. Dis. 7, 815-823.

Dabassa, A. and Bacha, K., 2012. The prevalence and antibiogram of Salmonella and Shigella isolated from abattoir, Jimma Town, South West Ethiopia. J. Int. Pharm. Biol. Res. 3,143-148.

Ejeta, G., Molla, B., Alemayehu, D. and Muckle, A., 2004._Salmonella serotypes isolated from minced meat beef, mutton and pork in Addis Ababa, Ethiopia. Rev. Med. Vet., 155, 547-551.

Fadlalla, I., Hamid, M., Abdel-Rahim, A. and Ibrahim, M., 2012. Antimicrobial susceptibility of Salmonella serotypes isolated from human and animals in Sudan. $J$. Public Health Epidemiol. 4, 19-23.

Fluit, A., 2005. Towards more virulent and antibiotic-resistant Salmonella. FEMS, Immunol. Med. Microbiol., 43, 1-11.

Forshell, L. and Wierup, M., 2006. Salmonella contamination: a significant challenge to the global marketing of animal food products. Rev. Sci. Tech. Off. Int. Epiz., 25,541-554

Guibourdenche, M., Roggentin, P., Mikoleit, M., Fields, I., Bockemuhl, J., Grimont, P., Weill, F., 2010. Supplement 2003-2007 (No. 47) to the White-Kauffmann-Le Minor scheme. Res. Microbiol., 161, 26-29.

Guthrie, R., 1992. Salmonella. CRS press: USA, Pp. 23-156.

Hailu, D., Gelaw, A., Molla, W., Garedew, L., Cole, L. and Johnson, R., 2015. Prevalence and antibiotic resistance patterns of Salmonella isolates from lactating cows and in-contact humans in dairy farms, Northwest Ethiopia, J Environ Occup Sci. 4, 171-178

Hendriksen, R., 2003. A global Salmonella surveillance and laboratory support project of the World Health Organization: Laboratory Protocols (Isolation of Salmonella). (4 $4^{\text {th }}$ Edition), Pp. 253-278.

Hoelzer, K., Moreno, Switt, A. and Wiedmann, M., 2011. Animal contact as a source of human non-typhoidal Salmonellosis. Vet. Res., 42, 34.

ISO-6579, 2002. Microbiology. General guidance methods for the detection of Salmonella (4 $4^{\text {th }}$ Edition). International organization for stnadardization, Geneva, Switzerland. Pp. 132-146.

Karin, H., Andrea, I. and Martin, W., 2011. Animal contact as a source of human nontyphoidal salmonellosis. J. Vet. Res., 42,1-28.

Ethiop. Vet. J., 2017, 21 (2), 92-108 
Kusumaningrum, H., Riboldi, G., Hazeleger, W. and Beumer, R., 2003. Survival of foodborne pathogens on stainless steel surfaces and cross-contamination to foods. Int J. Food Microbiol., 85, 227-236.

Liza, R., 2003. Salmonella Dublin in dairy cattle, use of diagnostic tests for investigation of risk factors and infection dynamics. PhD Thesis, Department of Animal Science and Animal Health, the Royal Veterinary and Agricultural University, Copenhagen. Pp. 13-121.

Mahami, T., Odonkor, S., Yaro, M. and Adu-Gyamfi, A., 2011. Prevalence of antibiotic resistant bacteria in milk sold Accra. J. Int. Res. Microbiol., 2,126-132.

Mathew, A., Cissell, R. and Liamthong, S., 2007. Antibiotic Resistance in Bacteria Associated with Food Animals: A United States Perspective of Livestock Production. Foodborne Pathog. Dis 4,115-133.

McCuddin, Z.P., Carlson, S.A., Rasmussen, M.A., and Franklin, S.K., 2006. Klebsiella to Salmonella gene transfer within rumen protozoa: implications for antibiotic resistance and rumen defaunation. Vet. Microbiol. 114, 275-284.

McGeer, A., 1998. Agricultural antimicrobials and resistance in human pathogens. JCMA.,159, 1190-1120.

Mohamed, O., Farid, A., Abaza, A. and Faltas, R., 2011. Faecal Shedding of Non-typhoid Salmonella Species in Dairy Cattle and their Attendants in Alexandria Suburbs. J. Am. Sci., 7, 623-629.

Molla, B., Mesfin, A. and Alemayehu, D., 2003. Multiple antimicrobial resistant Salmonella serotypes isolated from chicken carcasses and giblets in Debre Zeit and Addis Ababa, Ethiopia. Ethiop. J. Hlth. Dev., 17, 131-149.

Molla, W., Molla, B., Alemayehu, D., Muckle, A., Cole, L. and Wilkie, E., 2006. Occurrence and antimicrobial resistance of Salmonella serovars in apparently healthy slaughtered sheep and goats of central Ethiopia. Trop. Anim. Hlth. Prod., 38, 455462.

Murase, T., Yamada, M., Muto, T., Matsushima, A. and Yamai, S., 2000. Fecal excretion of Salmonella enterica serovar Typhimurium following a food-borne outbreak. J. Clin. Microbiol., 38, 3495-3497.

Plym, F. and Wierup, M., 2006. Salmonella contamination: a significant challenge to the global marketing of animal food products._Rev. Sci. Tech Off. Int. Epiz., 25, 541-554.

Rotimi, V., Jamal, W., Pal, T., Sonnevend, A., Dimitrov, T. and Albert, M., 2008. Emergence of multidrug resistant Salmonella spp. and isolates with reduced susceptibility to ciprofloxacin in Kuwait and the United Arab Emirates. Diagn. Microbiol. Infect. Dis., 60, 71-77. 
Stella, S., Moses, B. and Helen, A., 2009. Antimicrobial Susceptibilities of Salmonellae Isolated from Food Handlers and Cattle in Lagos, Nigeria. J. Int. Hlth. Res., 2, 189-193.

Stevens, A., Kabore, Y., Perrier-Gros-Claude, J., Millemann, Y., Brisabois, A., Catteau, M., Cavin, J. and Dufour, B., 2006. Prevalence and antibiotic-resistance of Salmonella isolated from beef sampled from the slaughterhouse and from retailers in Dakar (Senegal). Int. J. Food Microbiol., 110, 178-186.

Tadesse, T. and Anbessa, D., 2012. Prevalence and antimicrobial resistance of Salmonella isolated from raw milk samples collected from Kersa District, Jimma Zone, South-West Ethiopia. J. Med. Sci., 12, 224-228.

Tajbakhsh, F., Tajbakhsh, E., Momeni, M., Rahimi, E. and Sohrabi, R., 2012. Occurrence and Antibiotic Resistance of Salmonella spp isolated from raw Cow's Milk from Shahahrekord. Iran. Inter. J. Microbiol. Res., 3, 242-245.

Teklu, A. and Negussie, H., 2011._Assessment of risk factors and prevalence of Salmonella in slaughtered small ruminants and environment in an export abattoir, Modjo, Ethiopia. American-Eurasian J. Agric. Environ. Sci., 10, 992-999.

Thrusfield M., 2007. Veterinary epidemiology. 3rd edition London: Blackwell Science. Pp. 227-247.

Uzzau, S., Leori, G., Petruzzi, V., Watson, P. and Schianchi, G., 2001. Salmonella enterica Serovar-Host Specificity Does Not Correlate with the Magnitude of Intestinal Invasion in Sheep. Infect. Immun., 69, 3092-3099.

WHO 2010. Global Food bore Infections Network. Laboratory Protocol "Isolation of Salmonella spp. From Food and Animal Faeces" $5^{\text {th }}$ Edition.

Zewdu, E. and Cornelius, P., 2009. Antimicrobial resistance pattern of Salmonella se-rotypes isolated from food items and personnel in Addis Ababa, Ethiopia. Trop. Anim. Hlth. Prod., 41, 241-249. 